\title{
Seasonal and interplanetary magnetic field dependence of the field-aligned currents for both Northern and Southern Hemispheres
}

\author{
D. L. Green ${ }^{1}$, C. L. Waters ${ }^{1}$, B. J. Anderson ${ }^{2}$, and H. Korth ${ }^{2}$ \\ ${ }^{1}$ School of Mathematical and Physical Sciences, University of Newcastle, Callaghan, NSW, Australia \\ ${ }^{2}$ Johns Hopkins University Applied Physics Laboratory, Laurel, MD, USA \\ Received: 6 May 2008 - Revised: 18 December 2008 - Accepted: 18 February 2009 - Published: 8 April 2009
}

\begin{abstract}
The configuration of the Earth's magnetosphere under various Interplanetary Magnetic Field (IMF) and solar wind conditions alters the global distribution of FieldAligned Currents (FACs) at the high latitude ionospheres. We use magnetic field data obtained from the Iridium constellation to extend recent studies that infer the dependence of the global FAC configuration on IMF direction and magnitude, hemisphere and season. New results are a reduced IMF $B_{y}$ influence on the FAC configuration for the winter hemisphere and a redistribution of FAC to the nightside for winter relative to the summer hemisphere. These effects are linked to the winter ionosphere conductance distribution being dominated by localised nightside enhancement associated with ionisation from energetic particle precipitation. A comparison of an estimated open-closed field line boundary (OCFLB) with the Region 1 FAC locations shows reasonable agreement for summer FAC configurations. However, the OCFLB location is decoupled from the Region 1 FACs in winter, especially for IMF $B_{z}>0$.
\end{abstract}

Keywords. Ionosphere (Auroral ionosphere; Electric fields and currents) - Magnetospheric physics (Current systems)

\section{Introduction}

The interaction between the solar wind and interplanetary magnetic field (IMF) with the Earth's magnetic field generates a system of global-scale electrical currents in the nearEarth space environment. Birkeland (1908) first suggested that a system of field-aligned currents (FACs) flowed in the upper atmosphere. These currents couple energy from the magnetosphere to the high latitude conducting ionospheres. Since the first in-situ satellite observations of transverse

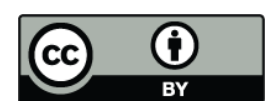

Correspondence to: D. L. Green (david.lindsay.green@gmail.com) magnetic perturbations associated with FACs (Zmuda et al., 1966; Cummings and Dessler, 1967; Zmuda et al., 1970; Armstrong and Zmuda, 1970), there has been a great deal of research to characterise their spatial and temporal variability (e.g., Zanetti et al., 1983; Potemra, 1985). The FAC configuration observed at low Earth orbit (LEO) altitudes reflects the structure of the magnetosphere. Therefore, a knowledge of the FAC distribution under various geomagnetic conditions is important for understanding energy transfer in the magnetosphere-ionosphere system.

Early studies of the global FAC distribution used data from LEO spacecraft averaged over many orbits to build a global picture. Average spatial distributions of the transverse magnetic perturbations associated with FACs were presented by Armstrong and Zmuda (1975) and Zmuda and Armstrong (1974a,b) who used vector magnetic field data from the TRIAD spacecraft and by Sugiura (1975) using OGO 5 magnetometer data. The first spatial distribution of FACs was obtained from TRIAD magnetometer data and used an average over 439 orbits (Iijima and Potemra, 1976a,b). This well known FAC configuration consists of Region 1 currents that flow into the ionosphere in the morning sector and away from the ionosphere in the evening sector. The Region 2 currents are located equatorward and have opposite polarity to Region 1. Statistically, the intensity of the Region 1 currents is larger than the Region 2 currents while the total integrated current into the ionosphere is equal to the amount flowing out of the ionosphere (Iijima, 2000). It is thought that the dayside Region 1 currents map to magnetic field lines that directly link with the solar wind dynamo while the nightside Region 1 currents map to closed field lines in the magnetosphere tail (Stern, 1983; Cowley, 2000). Region 2 currents map along closed field lines to the ring current region and are linked with the dynamics of the inner magnetosphere (Tanaka, 1995; Tsyganenko, 1993).

Observations of the FAC distribution in the topside ionosphere have shown that the IMF direction has a clear effect on

Published by Copernicus Publications on behalf of the European Geosciences Union. 
the configuration. For large IMF $B_{y}$ conditions there appears to be a "Region 0" current system, located poleward of Region 1 . Region 0 currents were initially named the cusp current (Iijima and Potemra, 1976a) and have also been called the "traditional cusp current" (Erlandson et al., 1988) and the "mantle current" (Bythrow et al., 1988) due to possible collocation with cusp particle precipitation. Following Ohtani et al. (2005b), we use the term "Region 0". The distribution of Region 0 and dayside Region 1 currents strongly depends on IMF $B_{y}$ (Iijima et al., 1978; Erlandson et al., 1988). The polarity of the Region 0 currents is controlled by the sign of IMF $B_{y}$ and they appear to be an extension of Region 1. The basic FAC distribution presented by Iijima and Potemra (1976a) is most representative of the configuration for southward (negative) IMF $B_{z}$. Iijima (1984), Zanetti et al. (1984) and Iijima and Shibaji (1987) reported the so called NBZ currents which occur poleward and with opposite polarity to Region 1 during periods of northward (positive) IMF.

There have been a number of statistical studies that have examined the seasonal dependence of the average latitude and intensity of the FACs. Fujii et al. (1981) used TRIAD satellite observations to show that the average latitude of dayside FACs in summer is $1^{\circ}-3^{\circ}$ poleward of the average winter location. More recently, Christiansen et al. (2002) using magnetometer data from the Oersted spacecraft reported that the average dayside FAC location is shifted poleward in summer relative to winter, decreasing the over-the-pole distance between the daytime and nighttime current systems by $4^{\circ}$. However, the same analysis of Magsat data showed that the dawn-dusk cross polar cap distance of the Region 1/Region 2 currents had little seasonal dependence. Ohtani et al. (2005b) examined the seasonal change in the location of dayside FACs using DMSP data and showed a relative difference of up to $5^{\circ}$ between the poleward summer and equatorward winter locations. In contrast to the Oersted results of Christiansen et al. (2002), Ohtani et al. (2005b) found that the nightside FACs moved equatorward in summer and poleward in winter with a maximum shift of $4^{\circ}$. These conflicting results were attributed to different definitions of FAC location. Ohtani et al. (2005b) compared their FAC locations with the Tsyganenko (1996) magnetic field model and concluded that the effect of the dipole tilt angle was the main cause of the annual variation in FAC latitude. Ohtani et al. also examined the dawn-dusk seasonal dependence. They reproduced the result from the Oersted data of Christiansen et al. (2002) but also revealed a semi-annual latitudinal variation of $\sim 1^{\circ}$ in average FAC location in the flank sectors. This was attributed to expansion of the auroral oval during the higher geomagnetic activity equinoxes.

Analyses of the seasonal variation have shown that the average total FAC is larger in summer compared with winter by a factor of 1.35 (Papitashvili et al., 2002) and between 1.5 and 1.8 (Christiansen et al., 2002). Ohtani et al. (2005b) extended this analysis and showed that the dayside Region 1 current intensity varies by a factor of 2 to 3 over the entire dipole tilt angle range. They also showed that the seasonal variation of the nightside FACs was more complicated with the nightside Region 2 current intensity more intense during winter than in summer.

Recent statistical studies using low Earth orbit (LEO) satellites has begun to characterise the variation of the global FAC distribution in both latitude and local time for varying IMF conditions, hemisphere and season. Accurate observations of the FAC response to varying driving conditions are essential for the development of realistic global magnetosphere models. The first comprehensive empirical model of the FAC distribution was developed by Weimer (2001) and based on in-situ magnetic field observations from the Dynamics Explorer 2 spacecraft. This model is parameterised by IMF, solar wind velocity, solar wind density and dipole tilt angle. Papitashvili et al. (2002) also developed an empirical model for the FAC distribution based on Magsat and Oersted spacecraft magnetic field data. They extended the results of Weimer (2001) by investigating the hemispheric dependence of the FAC distribution and the ground state (IMF $\sim 0$ ) patterns.

Anderson et al. (2008) presented average FAC maps for the Northern Hemisphere derived from magnetic field observations obtained from the Iridium satellite constellation. The average Northern Hemisphere, Iridium FAC maps for southward IMF and the model results presented by Papitashvili et al. (2002) for Northern Hemisphere summer showed broad agreement. However, Papitashvili et al. (2002) showed NBZ currents for southward IMF while Anderson et al. (2008) did not. Papitashvili et al. (2002) also reported larger R1 and R2 currents compared with the NBZ system, for northward IMF while Anderson et al. (2008) showed that the NBZ current densities were larger than the R1 and R2 currents. Furthermore, Papitashvili et al. (2002) presented the averaged FAC data sorted by hemisphere while Anderson et al. (2008) showed Northern Hemisphere FAC patterns.

In this paper we extend the results of Anderson et al. (2008) by presenting both the Northern and Southern Hemisphere FAC patterns and the average FAC distributions as a function of season, IMF direction and magnitude, including the case for near zero IMF magnitude. We use magnetic field data obtained from the Iridium constellation which is capable of monitoring the global FAC distribution on hourly timescales as opposed to using many single satellite passes to build the average pattern. As discussed by Green et al. (2008), previous FAC studies using Iridium data have focused mostly on the Northern Hemisphere due to uncertainties in the Southern Hemisphere FAC reconstruction. This is associated with the offset between the Iridium orbit plane intersection point and the geomagnetic pole. Green et al. (2008) investigated the basis functions used for estimating the Southern Hemisphere FAC data and showed that the Elementary Current Method (ECM) (Amm, 2001) yields improved FAC values compared with using the Spherical Cap Harmonic Analysis (Green et al., 2006). For this study all 
FAC maps are calculated using the ECM. The location of the Region 1 FACs has been linked to the open-closed field line boundary (OCFLB) (Cowley, 2000). We compare the location of an average OCFLB estimated from the Tsyganenko and Sitnov (2005) TS05 magnetic field model with the FAC distributions. We only consider stable FAC patterns, excluding storm time data intervals. The selection of the event list is discussed in Sect. 2. In Sect. 3 we present the average FAC maps and discuss these results with respect to the estimated OCFLB.

\section{Event selection}

Statistical studies of the FAC distribution based on single satellite observations (e.g., Weimer, 2001; Papitashvili et al., 2002) averaged all data in the same bin of geomagnetic conditions. Therefore, changes in the FAC distribution that occurred during all selected data intervals are averaged over all these configurations. For the present study we derived the global FAC configuration from magnetic field data obtained by the Iridium satellites. Data accumulated over a one hour period is usually required to provide sufficient data to the fitting algorithm. A more representative pattern is obtained when the FACs show little to no variation over the one hour interval (see Anderson et al., 2000; Waters et al., 2001). We have processed all available Iridium data from September 1999 through to December 2006 and selected intervals where the current patterns are stable.

Identification and selection of events was achieved by the following procedure: (a) The FAC patterns were calculated using a one hour data accumulation time stepped by $20 \mathrm{~min}$ intervals, giving around 165000 FAC maps. (b) Each FAC map was compared with the preceding 6 maps $(2 \mathrm{~h})$ for similarity. The large number of events required an automated process for identifying "similarity". (c) Numerical values for "similarity" were calculated from the 2-D cross correlation coefficient between the FAC map under scrutiny and the preceding 6 maps. The total of these correlation values is a number between -6 and 6 . (d) A threshold correlation value greater than or equal to +4 defines an event. This value was chosen based on FAC maps that were judged stable by manual inspection. We confine the events to those obtained during the months of December, January, February (northern winter and southern summer) and June, July, August (northern summer and southern winter) to give a total of 3250 , one hour events.

The procedure for selecting events from the Iridium data set differs from the IMF variability based stability estimates used in previous studies (e.g., Korth et al., 2008; Green et al., 2006). Anderson et al. (2008) used a more direct event selection method based on a comparison of consecutive one hour, non-overlapping FAC patterns and independent of the IMF parameters. The process involved the identification of FAC features in each map followed by a check for tempo-

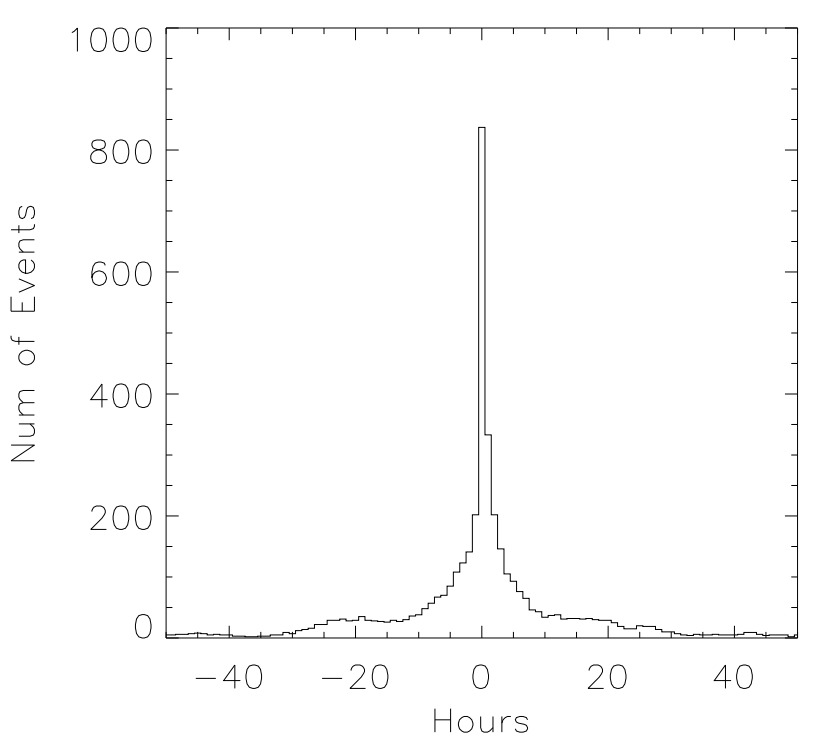

Fig. 1. Histogram of minimum time differences between each of our 2380 events and those discussed in Anderson et al. (2008).

ral consistency within those regions. For the present study we have also used an event selection process that is based on the temporal stability of the FAC pattern and independent of IMF parameters. In order to check the relationship between the events selected by Anderson et al. (2008) and the process described above, we initially limited our data to the same time span (February 1999 to December 2005) and to Northern Hemisphere events. The 2-D correlation process for selecting events is less restrictive, giving 2380 events compared with 1340 identified by Anderson et al. (2008). For each of our events, the minimum time difference was found by comparing with the events of Anderson et al. (2008). A minimum time difference of zero identifies the same event. The histogram of all minimum time differences is shown in Fig. 1, illustrating the large overlap in the two populations.

The distribution of all events used in this paper (February 1999 to December 2006) with IMF clock angle, IMF magnitude and season is shown in Fig. 2, in a similar format to Papitashvili et al. (2002). There is a clear bias for southward IMF conditions as these result in larger currents. The distribution shows more events in the Northern Hemisphere (NH) summer compared with NH winter, Southern Hemisphere (SH) summer and SH winter. The circle sizes in Fig. 2 are proportional to the standard deviation of the IMF clock angles over the event hour. In general, the IMF clock angle variability is larger for southward IMF events. In order to compare with Papitashvili et al. (2002), the FAC patterns as a function of IMF clock angle are shown in Fig. 4 and 5 for the two NH summer cases where $\left|B_{\mathrm{IMF}}\right| \leq 4$ and $\left|B_{\mathrm{IMF}}\right|>4$. The limited number of events prevents resolving the FAC dependence on IMF magnitude for the $\mathrm{NH}$ winter, $\mathrm{SH}$ summer and $\mathrm{SH}$ winter in Figs. 6-8. 

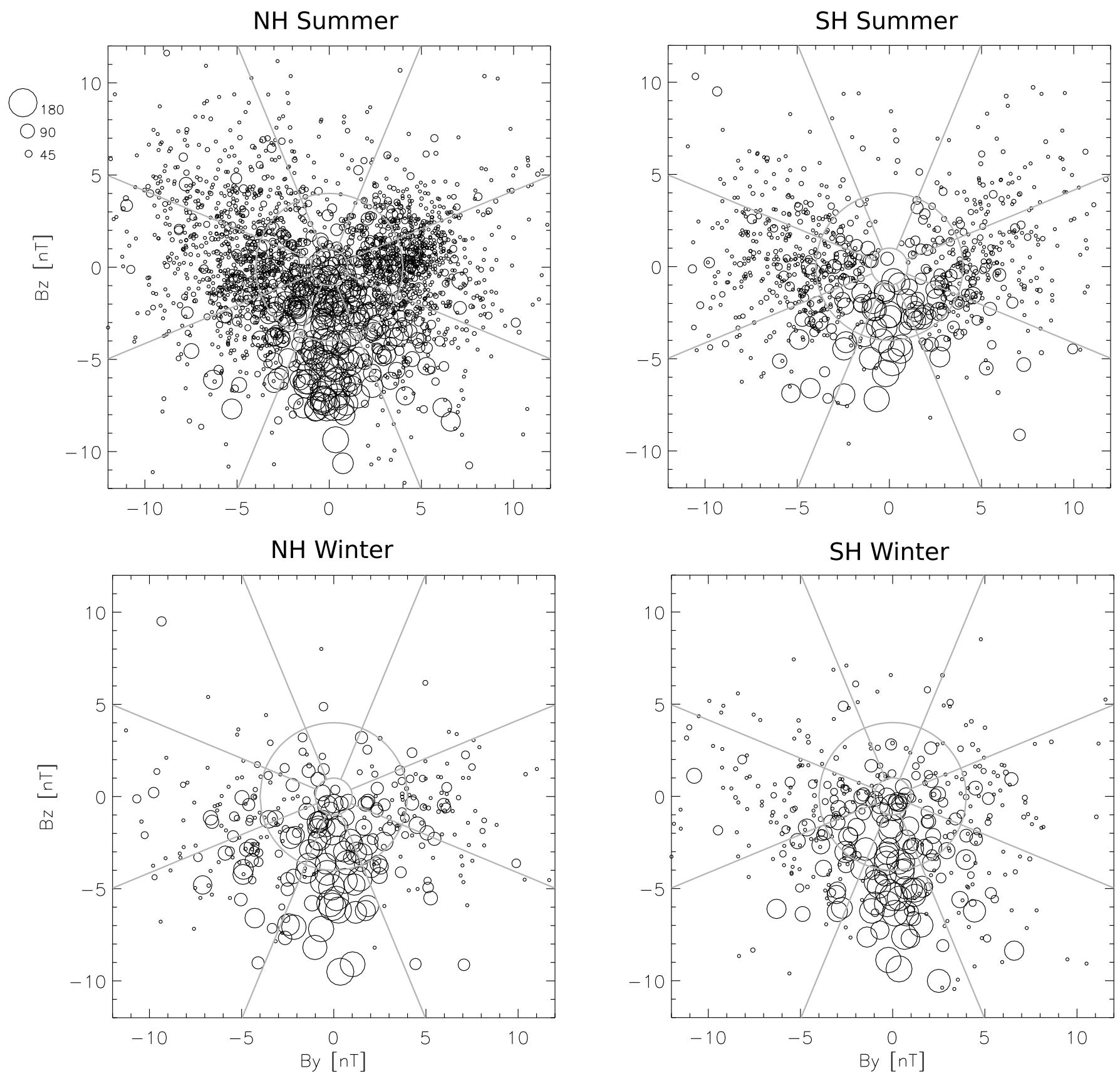

Fig. 2. IMF clock angle and magnitude distribution of stable field-aligned current events. Each panel is divided into eight clock angles and three IMF magnitude regions; $\left|B_{\mathrm{IMF}}\right| \leq 1,1<\left|B_{\mathrm{IMF}}\right| \leq 4$ and $4<\left|B_{\mathrm{IMF}}\right|$. The circle sizes represent the standard deviation of IMF clock angle during the one hour period for that event. A legend showing standard circle sizes is shown at the top left.

Figure 3 shows the distribution of the IMF magnitude for all the events. There is a bias toward $\left|B_{\mathrm{IMF}}\right|>4$ events in most of the IMF clock angle bins with the most common value around $5 \mathrm{nT}$.

\section{Results and discussion}

The NH summer FAC maps for $\left|B_{\mathrm{IMF}}\right| \leq 4$ are shown in Fig. 4. These show the usual patterns consistent with present understanding of the effect of the IMF direction. The three lower panels correspond to IMF $B_{z}<0$ showing the Region 1 (R1) and Region 2 (R2) current systems. For $B_{y}<0$ the morning sector R1 system moves into the polar cap while for 

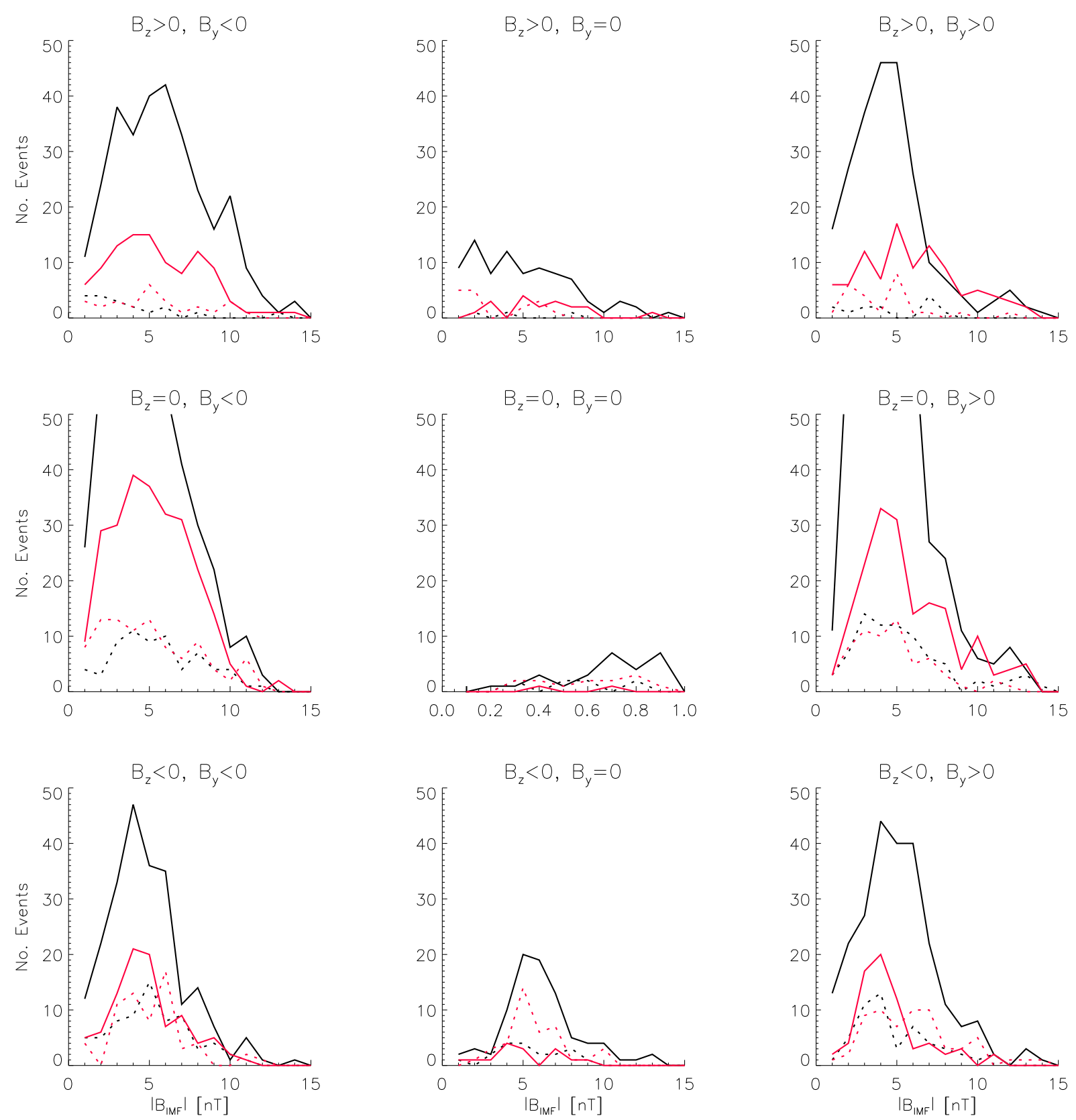

Fig. 3. IMF magnitude distribution of our events. NH curves are black while the SH are shown in red. Solid lines are for summer, dotted lines are for the winter hemisphere. Note the 0 to 1 IMF magnitude range for the center panel.

$B_{y}>0$ the evening sector R1 current extends toward the pole. While there are only seven stable events used in the construction of the $B_{z}<0, B_{y}=0$ map, the configuration appears to be consistent with the other panels.

The centre row configurations are for IMF $B_{z}=0$. The locations of the R1 and R2 currents are similar to the $B_{z}<0$ cases, shifted slightly poleward. However, the effect of IMF $B_{y}$ is more pronounced. For IMF $B_{y}<0$ the downward R1 system includes the pole while for IMF $B_{y}>0$, some upward
$\mathrm{R} 1$ current occurs at the pole. This is most probably the Region 0 (R0) current system identified in previous work (e.g., Iijima and Potemra, 1976a). The total integrated current is less for IMF $B_{z}=0$ than for IMF $B_{z}<0$ due to less solar wind energy entering the magnetosphere, and smaller again for the IMF $\sim 0$ configuration $\left(B_{z}=B_{y}=0\right.$, center panel). For IMF $\sim 0$, the FAC map shows a clear R1/R2 system with no R0.

The top row shows the average FAC patterns for IMF $B_{z}>0$. The effect of IMF $B_{y}$ dominates the configuration and 

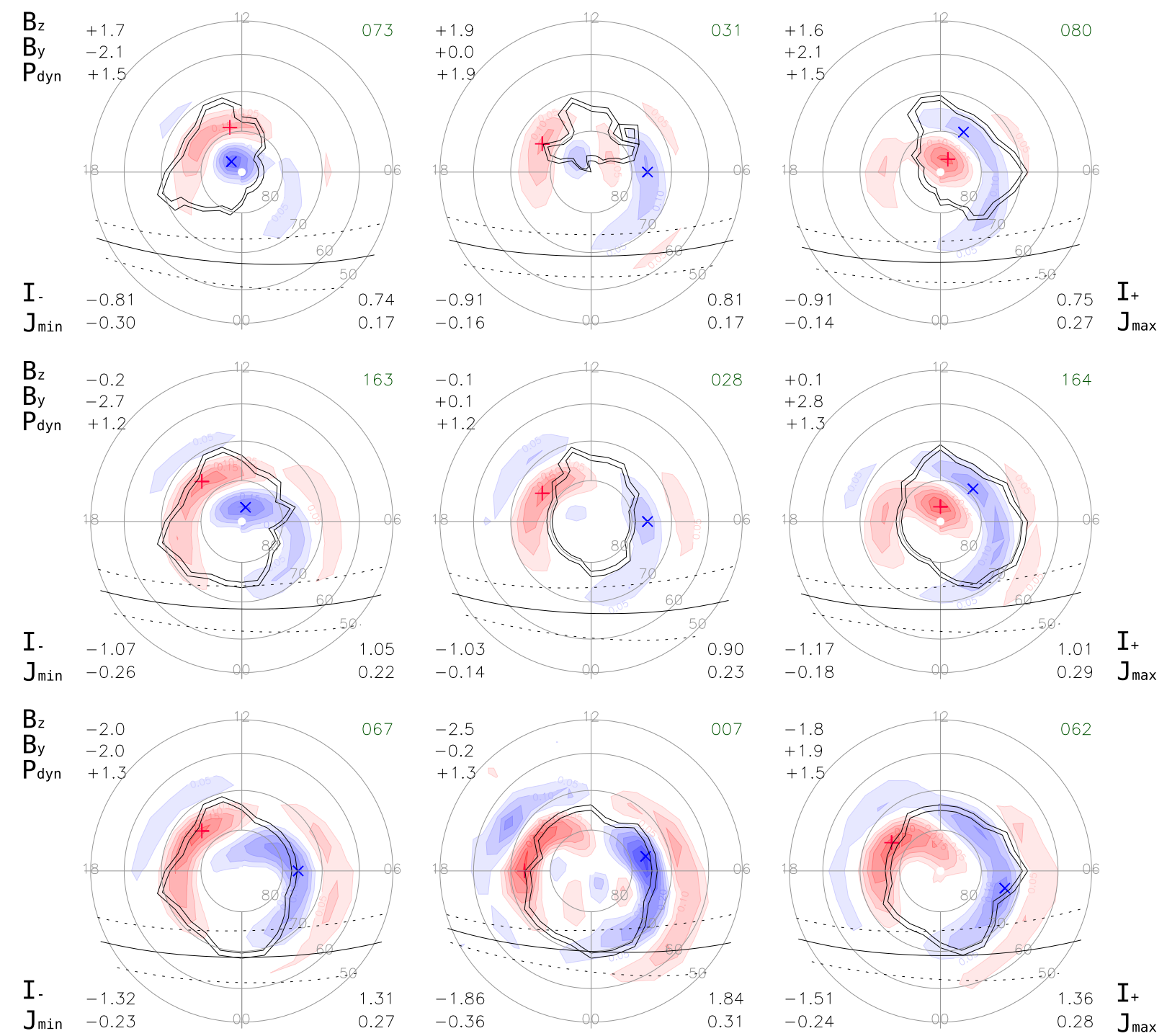

Fig. 4. Northern Hemisphere summer average field-aligned current distributions for $\left|B_{\mathrm{IMF}}\right| \leq 4$. Each panel shows the average of the number of events indicated at the top right (e.g. 73 for the top left panel). The mean IMF $B_{z}$ and $B_{y}$ (nT) and $P_{\text {dyn }}$ for these events are shown at the top left for each panel. The location of the maximum and minimum current densities are indicated by the " + " and " $x$ " symbols respectively. The current density values $\left(\mathrm{J} ; \mu \mathrm{Am} \mathrm{m}^{-2}\right)$ at these locations are the lower numbers at the bottom left (minimum) and bottom right (maximum). Total upward and downward current (I; MA) are shown just above the current density values. Red indicates upward current and blue is downward current. Contour levels are in $0.05 \mu \mathrm{Am}^{-2}$ steps. The approximate open-closed field line boundary calculated from the Tsyganenko and Sitnov (2005) field model for the mean IMF parameters is shown by the two black traces around the pole. All panels include the 1 standard deviation range in the location of the sunlit terminator. Coordinates are geomagnetic latitude and magnetic local time (MLT).

the R0 current becomes detached from the R1 system. The $\mathrm{R} 2$ currents are reduced in magnitude to below the Iridium detection limit $\left(\sim 0.01 \mu \mathrm{Am}^{-2}\right)$. For $B_{z}>0, B_{y}=0$ a clear $\mathrm{R} 1$ system is seen along with an NBZ current system with opposite polarity and poleward of R1.

Comparison between Figs. 4 and 5 shows the dependence of the FACs on IMF magnitude for the summer Northern Hemisphere. Essentially the spatial distribution of the currents is similar. The current density increases for the larger
IMF case with an associated equatorward expansion of $2-3^{\circ}$. Our Fig. 5 is very similar to Fig. 5 of Anderson et al. (2008) which represents the average FAC pattern for mostly summer events for the Northern Hemisphere along with strong solar wind driving conditions. We have placed the IMF $B_{y}>0$ patterns on the right, consistent with Weimer (2001) and Papitashvili et al. (2002). The IMF $B_{y}>0$ patterns are on the left in Fig. 5 of Anderson et al. (2008). 

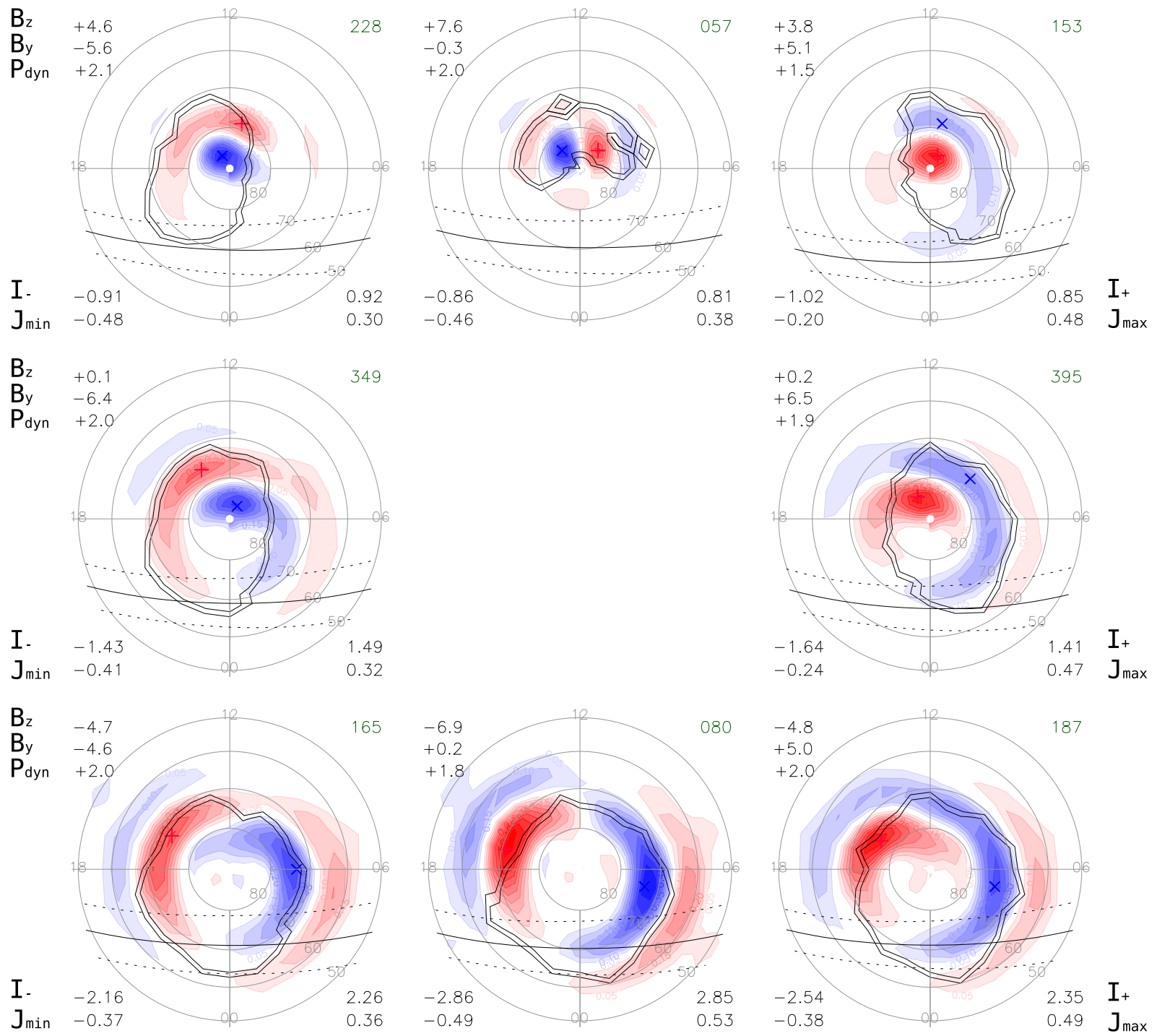

Fig. 5. Northern Hemisphere summer average field-aligned current distributions for $\left|B_{\mathrm{IMF}}\right|>4$. For full figure description see Fig. 4.

The FAC maps for NH winter are shown in Fig. 6. Comparing the IMF $B_{z}<0$ patterns (bottom row) with the summer patterns in Figs. 4 and 5 shows a relative MLT rotation in the location of the R1 and R2 current density maxima. In both Figs. 4 and 5 the maximum current densities of the evening sector R1 and R2 currents are located in the 12:0018:00 MLT quadrant. The winter FAC configuration in Fig. 6 shows the maximum current densities of the evening sector $\mathrm{R} 1$ and $\mathrm{R} 2$ currents has rotated relative to the summer locations to be in the 18:00-24:00 MLT quadrant. In contrast to the evening sector, the morning sector R1 and R2 current patterns remain essentially the same for the summer and winter.

The effect of IMF $B_{y}$ on the NH winter configurations is not as strong compared with the summer configurations. There is no extension of R1 into the polar cap for any IMF clock angle. It is also difficult to identify R0 currents in any of the winter patterns. In the top row, the FAC pattern for IMF $B_{z}>0, B_{y}=0$ does not show clear NBZ currents although only four FAC maps were available for this configuration. Stauning (2002) presented a statistical analysis of NBZ currents derived from Oersted magnetometer observations and showed that the NBZ system is only present in the summer hemisphere, consistent with our observations. They suggested that the absence of winter NBZ currents is due to the central polar cap ionosphere conductivity being an order of magnitude lower in winter compared with summer.

The most significant observational difference between our summer and winter FAC configurations is most easily seen when IMF $B_{z} \geq 0$ (top and middle rows of Fig. 6). The NH summer patterns (Figs. 4 and 5) show a configuration 

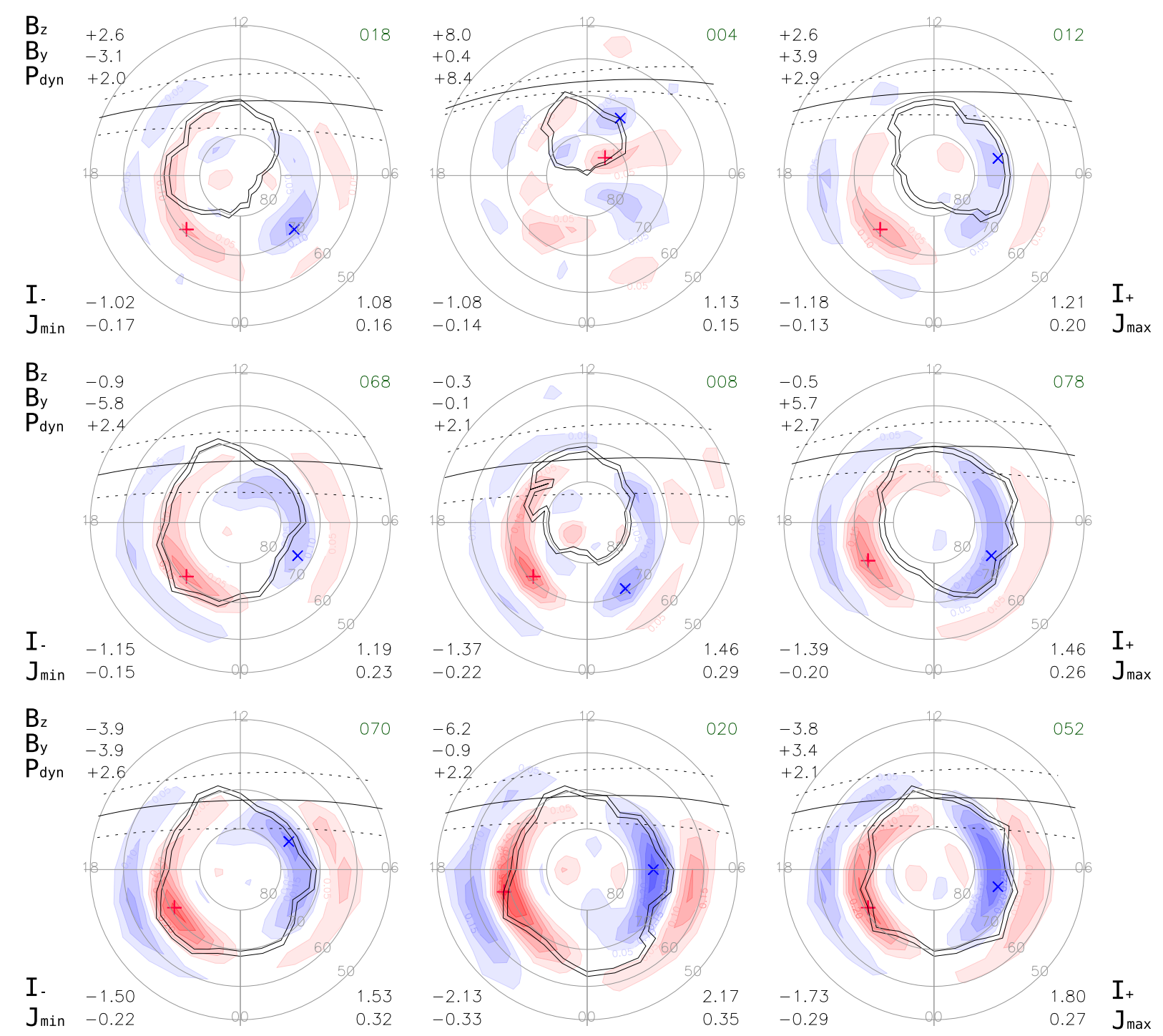

Fig. 6. Northern Hemisphere winter average field-aligned current distributions. For full figure description see Fig. 4.

dominated by IMF $B_{y}$ that extends R1 into R0 with the maximum current densities located on the dayside. In contrast, the NH winter currents show less effect with IMF $B_{y}$ and the afternoon to pre-midnight sector R1 and R2 current density maxima move toward the nightside in winter. The winter patterns include all IMF magnitudes which may result in some equatorward expansion compared with the summer $\left|B_{\mathrm{IMF}}\right| \leq 4$.

\subsection{Summary of seasonal FAC observations}

There are a number of observational differences between the NH summer and winter FAC configurations: (i) For IMF $B_{z}<0$ there is a MLT shift from the summer location of the evening sector R1 and R2 current density maxima toward the nightside. (ii) The skewing effect of IMF $B_{y}$ seen in the summer configurations is reduced for the winter configurations with no clear R0 current system for any IMF direction in winter. (iii) The NBZ current system seen for IMF $B_{y}=0$, $B_{z}>0$ in summer is not seen in winter. (iv) The winter R1 and $\mathrm{R} 2$ configuration for $B_{z} \geq 0$ is considerably different from the corresponding summer configuration with the R1 and R2 currents clearly shifted to the nightside in winter. The following sections discuss possible explanations for these observations.

The seasonal differences in the FAC patterns might suggest effects related to the Earth's dipole tilt angle, location of the OCFLB or effects related to solar illumination and the distribution of ionospheric conductivity over the polar regions. Ohtani et al. (2005b) suggested that the seasonal change in the geomagnetic field configuration may explain the poleward shift in the location of the dayside FACs in 

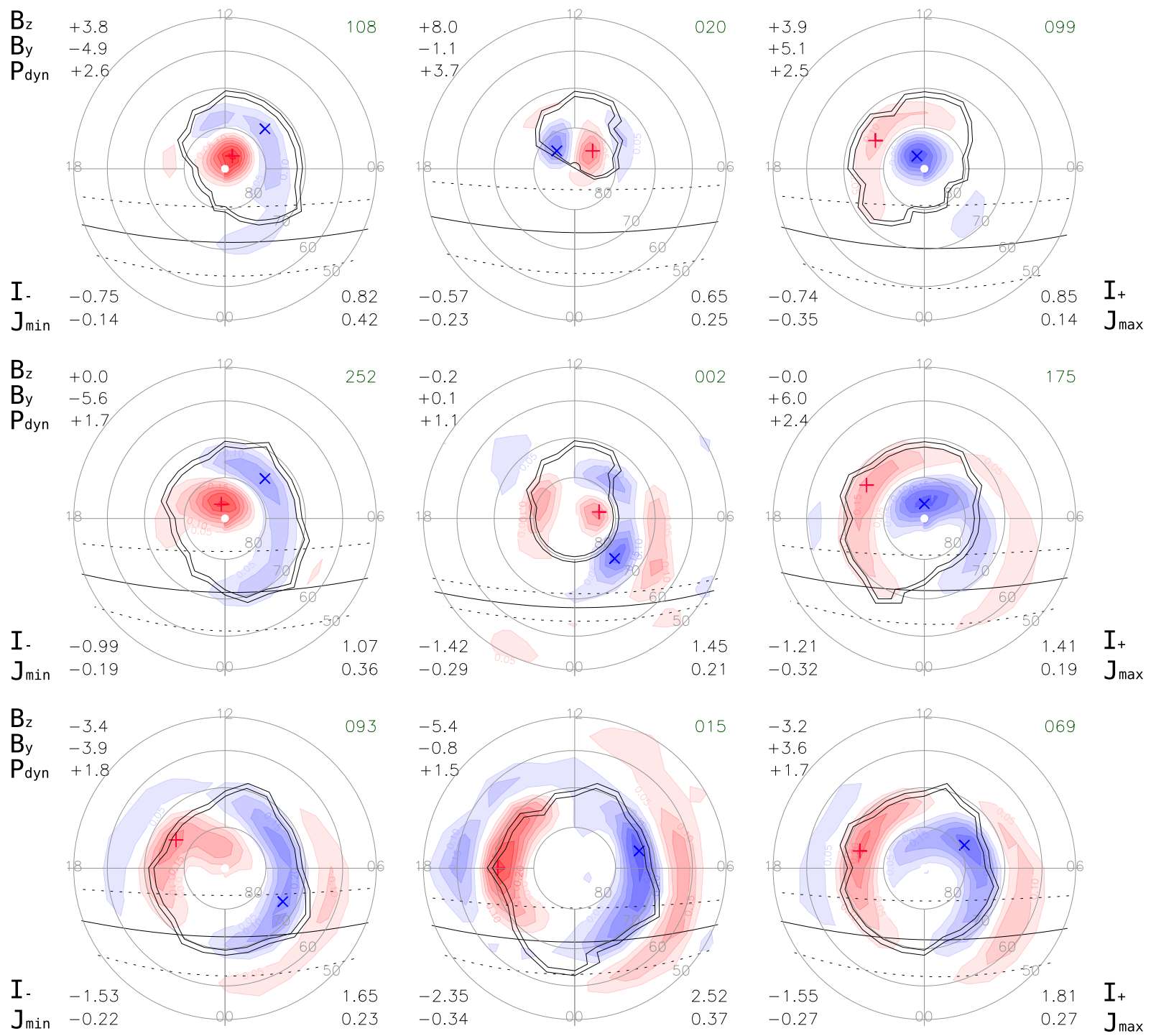

Fig. 7. Southern Hemisphere summer average field-aligned current distributions viewed as seen from above the Northern Hemisphere through the Earth. For full figure description see Fig. 4.

summer compared with winter since the dayside R1 currents are thought to be located near the OCFLB. In order to investigate this we have overlayed on each FAC map an average OCFLB estimated from the Tsyganenko and Sitnov (2005) TS05 magnetic field model for the mean IMF and solar wind conditions associated with the events used in constructing each FAC map. A full description of how the OCFLB was estimated is given in Appendix A. We would expect the latitudes of the dayside R1 currents and the OCFLB to be similar. The question of where the nightside R1 currents flow into the tail region is less well known and may not coincide with the model OCFLB.

The OCFLB and dayside R1 locations in Figs. 4 and 5 generally appear to coincide. The OCFLB contracts for more positive IMF $B_{z}$ values, shifts toward the evening sector for IMF $B_{y}<0$ and toward morning for IMF $B_{y}>0$, consistent with IMF $B_{y}$ skewing of the FAC pattern. For $B_{z}>0, B_{y}=0$ the OCFLB contracts and shifts toward the dayside, surrounding the NBZ currents, being co-located with R1. The equatorward expansion of the FACs for increasing IMF magnitude (i.e. from Fig. 4 to 5) is also mirrored by an equatorward expansion of the OCFLB.

The OCFLB are also shown on the NH winter FAC maps in Fig. 6. The winter OCFLB appears to follow the NH summer OCFLB shapes for $\left|B_{\mathrm{IMF}}\right| \leq 4$, rather than following the changes seen in the FAC patterns. Figure 6 shows the OCFLB estimate is reasonably well co-located with R1 for $B_{z}<0$. For $B_{z} \geq 0, B_{y} \leq 0$ the OCFLB does not encompass 

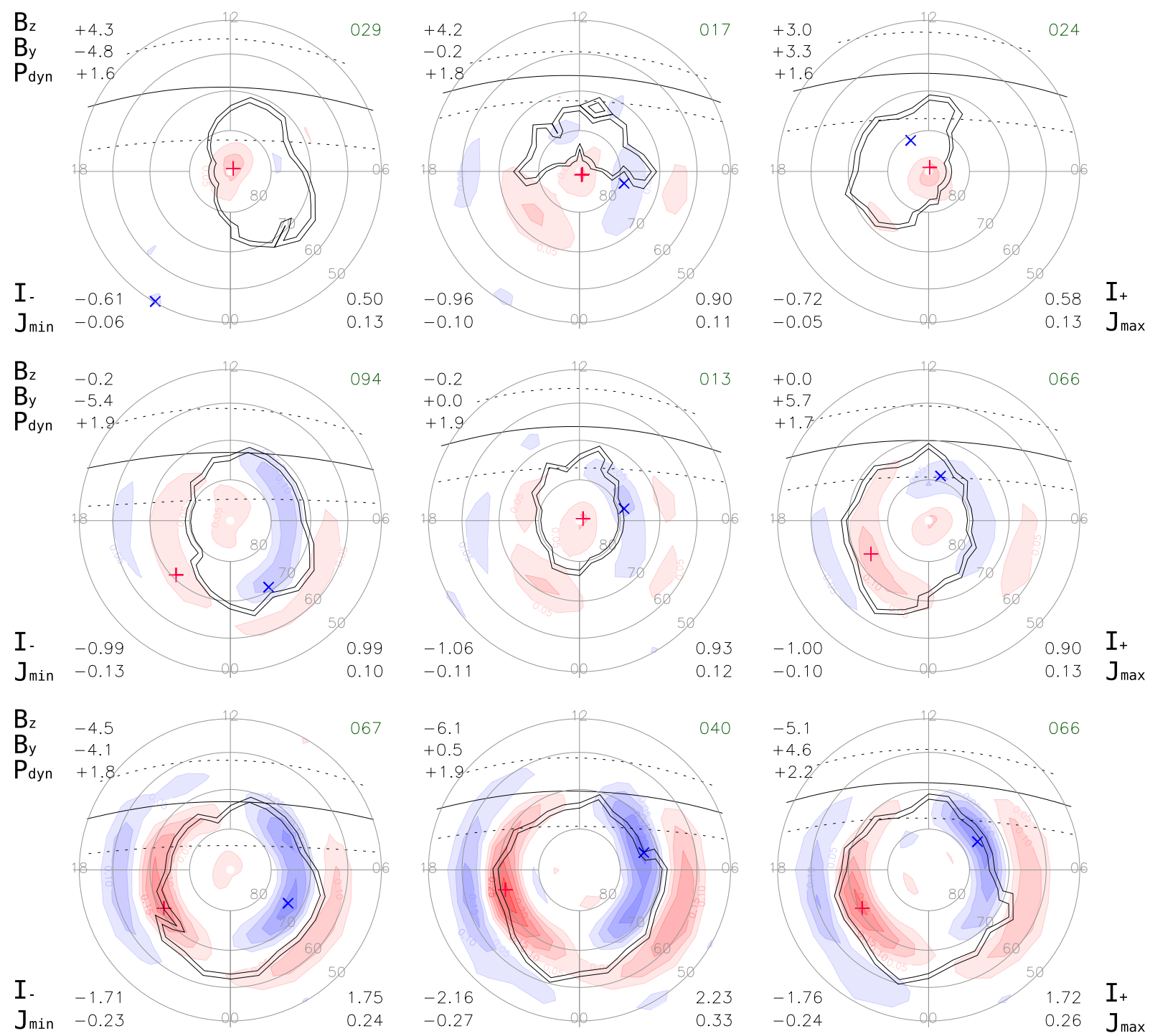

Fig. 8. Southern Hemisphere winter average field-aligned current distributions viewed as seen from above the Northern Hemisphere through the Earth. For full figure description see Fig. 4.

the morning side R1, nor is it co-located. The same is true for the afternoon to evening upward R1 current for $B_{z} \geq 0, B_{y} \geq 0$ which is maximum on closed field lines near 21:00 MLT.

In addition to the geomagnetic field configuration, the ionosphere conductance influences the FAC pattern (e.g., Fujii and Iijima, 1987; Ridley et al., 2004; Ohtani et al., 2005b). The ionosphere-magnetosphere interaction at FAC latitudes involves the ionosphere conductance and available electron density, the FAC energisation source, particle precipitation and auroral emissions. During summer a larger area of the high latitude ionosphere is illuminated by solar EUV radiation. The ionospheric conductivity has a solar EUV contribution which increases smoothly toward the dayside (Vickrey et al., 1981; Robinson and Vondrak, 1984; Rasmussen et al., 1988). Additionally there are localised conductance enhancements due to particle precipitation (Hardy et al., 1987), mostly from auroral particle acceleration. Upward FACs identified using Iridium data were shown to be colocated with far ultra-violet auroral emissions, particularly R1 on the duskside (Waters et al., 2001).

The effects on the FAC patterns due to ionosphere conductance may be related to the relative contributions of the particle compared to solar EUV conductance sources. On the dayside, both sources exist while on the nightside, the solar EUV is absent. During winter, most of the high latitude ionosphere is in darkness and the ionospheric conductivity would be dominated by the more localised enhancements due to particle precipitation. In order to identify the solar EUV 
contribution to the conductance in the FAC patterns, the sunlight terminator locations were calculated for each event and the mean location ( \pm 1 standard deviation) is shown on each FAC pattern. For the NH summer, over 95 percent of the $\mathrm{R} 1$ and $\mathrm{R} 2$ current systems are in sunlight for all IMF angles while for $\mathrm{NH}$ winter, the currents interact with a dark ionosphere. We see two consequences of the seasonal difference in ionospheric conductivity: The first is related to the background EUV conductance and the cause of item (ii) above. Figures 4, 5 and 7 show that for summer hemispheres the background EUV conductance allows extension of R1 into the polar cap in response to changes in IMF $B_{y}$. The lack of an EUV contribution in winter hemispheres means reduced polar cap conductance preventing the extension of R1 into the polar cap explaining the reduced IMF $B_{y}$ dependance seen in Figs. 6 and 8. The second is related to the particle induced condctance and the cause of item (i). While auroral particle induced conductance is localised in latitude, there is also a great deal of variation in MLT, around the auroral "ring". A number of studies have shown that auroral particle precipitation and emissions appear more intense in the winter compared with the summer hemisphere (Newell et al., 1996; Liou et al., 2001; Morooka et al., 2002), particularly in the 18:00-24:00 MLT quadrant. The afternoon R1 and R2 current density maxima move from afternoon daytime in summer to the dark pre-midnight sector in winter, suggesting a redistribution of the FACs in response to the nightside location of particle produced, enhanced ionospheric conductivity. This redistribution of FAC to the nightside may also explain the increased FAC intensities near midnight during winter relative to summer observed by Nakano et al. (2002) and Ohtani et al. (2005a). The transfer of FAC from the dayside in summer to the nightside in winter also appears to have an IMF dependence. For $B_{z}<0$, Figs. 6 and 4 show that the afternoon R1 and R2 currents are affected more than the dawnside currents. The cause of this dawn/dusk asymmetry is unclear. For $B_{z} \geq 0$, both the dawn and dusk side R1 and $\mathrm{R} 2$ currents move into the nightside for the winter.

\subsection{Southern Hemisphere}

The summer FAC maps for the SH are shown in Fig. 7. Comparing with the NH summer maps in Figs. 4 and 5 shows a similar FAC configuration. However, the effect of IMF $B_{y}$ is reversed. For $B_{z}<0$, and $B_{y}<0$ in the SH (Fig. 7) the dusk side R1 extends into the polar cap while for the NH (Fig. 4) the dawn side $\mathrm{R} 1$ is extended. This hemispheric asymmetry is due to the sunward reconnection point (where the IMF is anti-parallel to the Earth's main field) for $B_{y}<0$ located on the dusk side for the $\mathrm{SH}$ and dawn side for $\mathrm{NH}$.

A comparison of the SH summer (Fig. 7) and winter (Fig. 8) configurations for $B_{z} \leq 0$ shows some evidence for a redistribution of FAC toward the night side as was seen for the NH. For IMF $B_{z}=0$ the $\mathrm{SH}$ winter patterns show reduced $B_{y}$ influence and some movement of current to the nightside compared with the summer, particularly for IMF $B_{y}<0$. For IMF $B_{z}>0$ the SH winter patterns show some evidence of small currents with a configuration different to those of the $\mathrm{NH}$ winter. However, the magnitude of these currents are close to the noise floor and without further improvement in data resolution no definitive conclusions can be made.

Previous research has reported up to twice the average total FAC in summer compared with the winter hemisphere (Papitashvili et al., 2002; Christiansen et al., 2002). In order to determine the total average current values for summer compared with winter from our data, we selected the stable events that were common to both the NH and SH. This subset of the events was then used to produce average FAC patterns sorted by IMF clock angle. The ratios of the total average currents for summer compared with winter hemispheres for these events are listed in Table 1. The average current ratios for summer compared with winter range from around unity to 2 .

Table 1 indicates that the average SH currents are smaller than those in the NH. This difference can be explained in terms of the Iridium orbit configuration. The current densities were estimated from the cross-track component of the Iridium magnetic field measurements. At present the alongtrack component of the magnetic field is not recoverable (Anderson et al., 2000). Therefore, the angle between the Iridium tracks and the large-scale FAC sheets affects the magnitude of the cross-track perturbation. Since the intersection point of the Iridium orbit planes is approximately co-located with the geographic pole there is a difference between the angle at which the Iridium tracks cut the geomagnetic aligned FACs in the south compared with the Northern Hemisphere. Preliminary analyses shows that on average, current densities derived from the Iridium data in the $\mathrm{SH}$ are smaller by around 10 percent compared with $\mathrm{NH}$ values. This would tend to inflate the $\mathrm{NH} / \mathrm{SH}$ and reduce the $\mathrm{SH} / \mathrm{NH}$ current ratios. If this factor is folded into the values in Table 1, the average current ratios for both $\mathrm{NH} / \mathrm{SH}$ and $\mathrm{SH} / \mathrm{NH}$ are similar at 1.3. We note that, taking into account the statistical scatter in our data and those in the data of Papitashvili et al. (2002) and Christiansen et al. (2002), our ratio of 1.3 and their ratios are regarded to be the same.

Given that the ionosphere conductance influences the FAC magnitude and pattern, we considered the possibility that the solar EUV contribution may introduce a local time dependence. This may affect the FAC patterns in each IMF bin if the events are from different local time distributions. We examined this by calculating the local time distribution of the events in each IMF bin. Focusing on the NH data for $B_{z} \leq 0$, the NH winter and summer events showed very similar local time distributions for $B_{y} \geq 0$. Since these data also show the shift in FAC from the day to nightside as we go from summer to winter, this is a seasonal rather than a local time effect. For the equinoxes, the sunlight terminator would vary near the 06:00-18:00 MLT line during the day which would enhance any local time variation in the FACs. Since our data 
Table 1. Ratios of the NH to SH total upward current ( $\mathrm{I}_{+}$in MA) and downward current (I- in MA) for the stable events common to both the NH and SH. The number of events for each IMF clock angle sector are shown in the Number column. The average and standard deviation for each column are shown in the bottom two rows.

\begin{tabular}{ccccccc}
\hline & \multicolumn{3}{c}{ NH Summer/SH Winter } & \multicolumn{3}{c}{ SH Summer/NH Winter } \\
IMF Clk Sector & $\mathrm{I}_{-}$ & $\mathrm{I}_{+}$ & Number & $\mathrm{I}_{+}$ & $\mathrm{I}_{-}$ & Number \\
\hline $\mathrm{N}$ & 1.5 & 1.4 & 7 & & & - \\
$\mathrm{NW}$ & 1.7 & 1.8 & 15 & 0.9 & 1.0 & 4 \\
$\mathrm{~W}$ & 1.4 & 1.5 & 32 & 1.4 & 1.4 & 12 \\
$\mathrm{SW}$ & 1.3 & 1.3 & 42 & 1.3 & 1.4 & 16 \\
$\mathrm{~S}$ & 1.4 & 1.3 & 29 & 1.2 & 1.2 & 8 \\
$\mathrm{SE}$ & 1.5 & 1.4 & 41 & 0.9 & 1.0 & 12 \\
$\mathrm{E}$ & 1.6 & 1.6 & 29 & 1.1 & 1.2 & 22 \\
$\mathrm{NE}$ & 1.9 & 1.9 & 10 & 0.9 & 1.1 & 5 \\
$\mid B_{\mathrm{IMF}} \leq 1 \mathrm{nT}$ & 1.2 & 1.4 & 4 & & & - \\
\hline Average & 1.5 & 1.5 & & 1.1 & 1.2 & \\
Std Dev & 0.2 & 0.2 & & 0.2 & 0.2 & \\
\hline
\end{tabular}

have been sorted into summer and winter events where the FACs are mostly either in sunlight or darkness, local time variations on the solar EUV conductance and FAC are much smaller than would be expected for the equinoxes.

\subsection{Comparison with empirical FAC models}

In general, our FAC configurations are consistent with empirical FAC model results for $\left|B_{\mathrm{IMF}}\right|=5 \mathrm{nT}$ presented in the supplementary material to Papitashvili et al. (2002). Differences between our results and the empirical model appear to be; (i) The results presented here are derived from the Iridium magnetometer data that have a minimum detection around $\sim 30 \mathrm{nT}$. The model results of Papitashvili et al. are based on high-precision magnetometer observations from the Oersted and Magsat satellites so the empirical model may include smaller FAC intensities as seen for SH winter for IMF $B_{z}>0$. (ii) Our results consider stable events only and this appears to contribute to some differences with the empirical model configurations. For example, for NH summer, IMF $B_{y}<0$ our results do not show the weak downward current near 21:00 MLT and 60 degrees. For NH winter, IMF $B_{z}<0$ the expansion of the morning sector R1 toward midday is not present in our results and in general, the location of both the R1 and R2 FACs are further poleward in our results. (iii) The empirical model configurations for winter IMF $B_{z}<0$ show an up/down current system located at the pole. Although this feature has a magnitude that should be detected by Iridium it is not present in our winter FAC maps. Possible reasons for this difference were discussed by Anderson et al. (2008).

\section{Conclusions}

A comprehensive description of the IMF direction and seasonal dependence of the global FAC distribution has been presented for both Northern and Southern Hemispheres. For the summer hemisphere, the FAC configuration is consistent with previous results in Weimer (2001), Papitashvili et al. (2002) and Anderson et al. (2008) showing a large dependence on IMF $B_{y}$ and equatorward expansion of the FACs for increased IMF magnitude. For winter, no NBZ currents are seen, similar to the results of Stauning (2002). We have found that the winter hemisphere shows a reduced dependence of the FAC configuration on IMF $B_{y}$ and that relative to summer, exhibits a redistribution of FAC to the nightside. The reduced IMF $B_{y}$ dependence and the redistribution may be a result of the winter ionospheric conductance being dominated by localised nightside enhancement associated with particle precipitation instead of the more distributed background conductance due to solar radiation that occurs in the summer hemispheres. We have presented the first comparison of the global FAC distributions with an estimate of the OCFLB location. There is reasonable agreement between the boundary location and dayside R1 FAC for summer. The FAC configuration was shown to be further decoupled from the OCFLB location in winter, especially for $B_{y}>0$. The average amount of current in the summer hemisphere is 1.3 times larger than the winter hemisphere.

\section{Appendix A}

\section{Estimation of the average OCFLB location}

The estimates of the average OCFLB location presented in Figs. 4 to 8 were calculated using the geomagnetic field line tracing routine (TRACE) provided as part of the GEOPACK software (http://geo.phys.spbu.ru/ tsyganenko/ modeling.html). The polar region was divided into a regular grid of $1 \mathrm{~h}$ spacing in local time and $2^{\circ}$ in latitude. At each point the geomagnetic field was traced away from the Earth's 


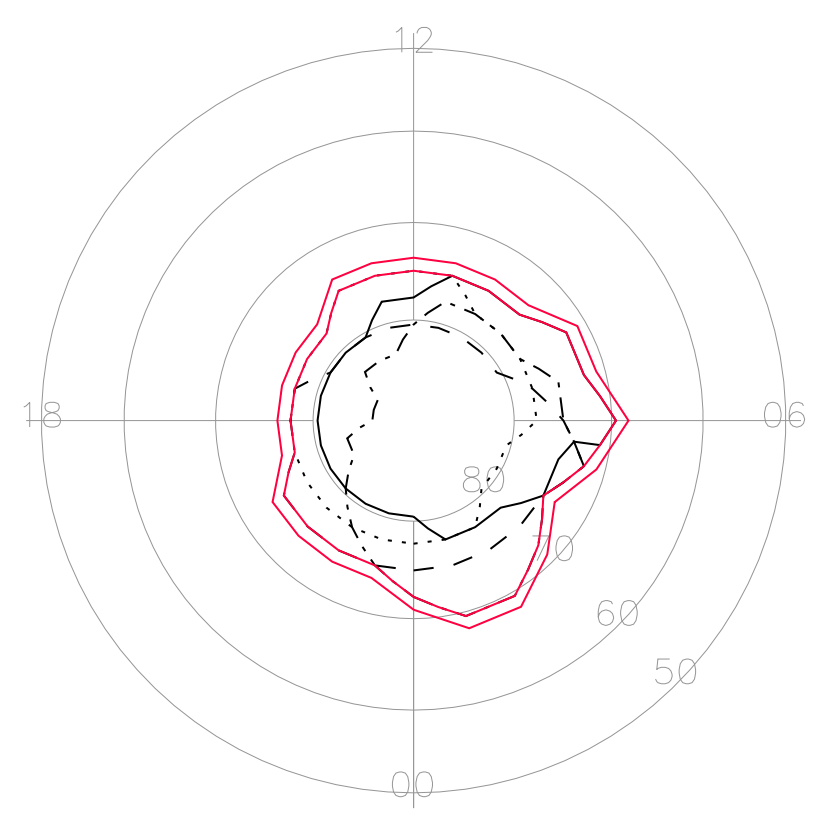

Fig. A1. Example estimation of the OCFLB for NH Summer Solstice 2004 (21 June, DOY=173) $B_{z}=-1.8 \mathrm{nT}, B_{y}=1.9 \mathrm{nT}$ and $P_{\text {dyn }}=1.5 \mathrm{nPa}$. Estimated boundaries are shown for 00:00 UT (solid), 06:00 UT (dotted), 12:00 UT (dashed) and 18:00 UT (dashdot) with the final estimate being that which encompasses all four estimates, i.e., the double red line. Coordinates are geomagnetic latitude and magnetic local time (MLT).

surface with that location flagged as outside the OCFLB if the footprint returned by the TRACE routine was not located at the Earth's surface in the opposite hemisphere. The Tsyganenko and Sitnov (2005) TS05 and International Geomagnetic Reference Field (IGRF) models were used for the summer (21 June 2004, DOY=173) and winter (22 December 2004, DOY=356) solstices. Inputs to the TSO5 model were the mean IMF $B_{z}$ and $B_{y}$ and $P_{\text {dyn }}$ values for the events included in the average FAC maps. The Dst index and the W1W6 indices were set to zero. The following TS05 options were used: iopGen $=0$ (General: Total Field), iopT $=0$ (Tail: Both Modes), iopB $=0$ (Birkeland: All 4 Terms), iopR=0 (Ring: Both SRC and PRC).

Due to the Earth's rotation, in the geomagnetic latitude and MLT coordinate system used here the OCFLB location will vary with time of day. We calculated an OCFLB at 00:00, 06:00, 12:00 and 18:00 UT with the final boundary (shown on Figs. 4 to 8 ) being that which encompassed all open field lines for the 4 times. An example is shown in Fig. A1 where the 4 individual boundary estimates are shown (black) in addition to the final estimate (red).

Acknowledgements. We thank the ACE SWEPAM instrument team and the ACE Science Center for providing the IMF data. The efforts of Iridium Satellite LLC in providing engineering magnetometer data for scientific analysis are deeply appreciated. This research was supported under the Australian Research Council Discovery Projects scheme and the National Science Foundation under grants ATM-9819804, ATM-0101064, and ATM-0334668.

Topical Editor M. Pinnock thanks F. Christiansen and another anonymous referee for their help in evaluating this paper.

\section{References}

Amm, O.: The elementary current method for calculating ionospheric current systems from multisatellite and ground magnetometer data, J. Geophys. Res., 106, 24843-24856, 2001.

Anderson, B. J., Takahashi, K., and Toth, B. A.: Sensing global Birkeland currents with Iridium engineering magnetometer data, Geophys. Res. Lett., 27, 4045-4048, 2000.

Anderson, B. J., Korth, H., Waters, C. L., Green, D. L., and Stauning, P.: Statistical Birkeland current distributions from magnetic field observations by the Iridium constellation, Ann. Geophys., 26, 671-687, 2008, http://www.ann-geophys.net/26/671/2008/.

Armstrong, J. C. and Zmuda, A. J.: Field-aligned current at 1100 $\mathrm{km}$ in the auroral region measured by satellite., J. Geophys. Res., 75, 7122-7127, 1970.

Armstrong, J. C. and Zmuda, A. J.: Triaxial magnetic measurements of field-aligned currents at 800 kilometers in the auroral region: initial results, J. Geophys. Res., 78, 6802-6807, 1975.

Birkeland, K.: The Norwegian Aurora Polaris Expedition 19021903, vol. 1, H. Aschehoug \& Co., Christiania, Norway, 1908.

Bythrow, P. F., Potemra, T. A., Erlandson, R. E., Zanetti, L. J., and Klumpar, D. M.: Birkeland currents and charged particles in the high-latitude prenoon region - A new interpretation, J. Geophys. Res., 93, 9791-9803, 1988.

Christiansen, F., Papitashvili, V. O., and Neubert, T.: Seasonal variations of high-latitude field-aligned currents inferred from Orsted and Magsat observations, J. Geophys. Res., 107, 1029-1045, 2002.

Cowley, S. W. H.: Magnetosphere-Ionosphere Interactions: A Tutorial Review, in: Magnetospheric Current Systems, edited by: Ohtani, S., Fujii, R., Hesse, M., and Lysak, R. L., Geophysical Monograph 118, pp. 91-106, American Geophysical Union, Washingtion, D.C., 2000.

Cummings, W. D. and Dessler, A. J.: Field-Aligned Currents in the Magnetosphere, J. Geophys. Res., 72, 1007-1013, 1967.

Erlandson, R. E., Zanetti, L. J., Potemra, T. A., Bythrow, P. F., and Lundin, R.: IMF B(y) dependence of region 1 Birkeland currents near noon, J. Geophys. Res., 93, 9804-9814, 1988.

Fujii, R. and Iijima, T.: Control of the ionospheric conductivities on large-scale Birkeland current intensities under geomagnetic quiet conditions, J. Geophys. Res., 92, 4505-4513, 1987.

Fujii, R., Iijima, T., Potemra, T. A., and Sugiura, M.: Seasonal dependence of large-scale Birkeland currents, Geophys. Res. Lett., 8, 1103-1106, 1981.

Green, D. L., Waters, C. L., Anderson, B. J., Korth, H., and Barnes, R. J.: Comparison of large-scale Birkeland currents determined from Iridium and SuperDARN data, Ann. Geophys., 24, 941959, 2006, http://www.ann-geophys.net/24/941/2006/.

Green, D. L., Waters, C. L., Korth, H., and Anderson, B. J.: Validation of Southern Hemisphere Field-Aligned Currents Calculated from Iridium Magnetic Field Data, in: Australian Space Science 
Conference Series, edited by: Short, W. and Cairns, I., National Space Society of Australia Ltd, GPO Box 7048 Sydney NSW 2001, ISBN 13: 978-0-9775740-1-8, 2008.

Hardy, D. A., Gussenhoven, M. S., Raistrick, R., and McNeil, W. J.: Statistical and Functional Representations of the Pattern of Auroral Energy Flux, Number Flux, and Conductivity, J. Geophys. Res., 92, 12275-12294, 1987.

Iijima, T.: Field-aligned currents during northward IMF, in: Magnetospheric currents; Chapman Conference, Irvington, VA, April 5-8, 1983, Selected Papers (A84-45751 22-46). Washington, D.C., American Geophysical Union, 1984, p. 115-122., pp. 115122, 1984.

Iijima, T.: TUTORIAL: Field-Aligned Currents in Geospace: Substance and Significance, pp. 107-129, Magnetospheric Current Systems, 2000.

Iijima, T. and Potemra, T. A.: The Amplitude distribution of fieldaligned currents at northern high latitudes observed by Triad, J. Geophys. Res., 81, 2165-2174, 1976a.

Iijima, T. and Potemra, T. A.: Field-Aligned Currents in the Dayside Cusp Observed by Triad, J. Geophys. Res., 81, 5971-5979, $1976 b$.

Iijima, T. and Shibaji, T.: Global characteristics of northward IMFassociated (NBZ) field-aligned currents, J. Geophys. Res., 92, 2408-2424, 1987.

Iijima, T., Fujii, R., Potemra, T. A., and Saflekos, N. A.: Fieldaligned currents in the south polar cusp and their relationship to the interplanetary magnetic field, J. Geophys. Res., 83, 55955603, 1978.

Korth, H., Anderson, B. J., Ruohoniemi, J. M., Frey, H. U., Waters, C. L., Immel, T. J., and Green, D. L.: Global observations of electromagnetic and particle energy flux for an event during northern winter with southward interplanetary magnetic field, Ann. Geophys., 26, 1415-1430, 2008,

http://www.ann-geophys.net/26/1415/2008/.

Liou, K., Newell, P. T., and Meng, C. I.: Seasonal effects on auroral particle acceleration and precipitation, J. Geophys. Res., 106, 5531-5542, 2001.

Morooka, M., Andre, M., Wahlund, J., Fazakerley, A., Winningham, D., Reme, H., Dandouras, I., Balogh, A., Lucek, E., Cornilleau-Wehrlin, N., and Buchert, S.: Dayside High Latitude Auroral Particle Acceleration Observed by the Cluster Satellites, AGU Fall Meeting Abstracts, pp. B533+, 2002.

Nakano, S., Iyemori, T., and Yamashita, S.: Net field-aligned currents controlled by the polar ionospheric conductivity, J. Geophys. Res. (Space Physics), 107, 1056, doi:10.1029/ 2001JA900177, 2002.

Newell, P. T., Meng, C.-I., and Lyons, K. M.: Suppression of discrete aurorae by sunlight., Nature, 381, 766-767, 1996.

Ohtani, S., Ueno, G., and Higuchi, T.: Comparison of largescale field-aligned currents under sunlit and dark ionospheric conditions, J. Geophys. Res. (Space Physics), 110, 9230, doi: 10.1029/2005JA011057, 2005a.

Ohtani, S., Ueno, G., Higuchi, T., and Kawano, H.: Annual and semiannual variations of the location and intensity of large-scale field-aligned currents, J. Geophys. Res. (Space Physics), 110, 1216, doi:10.1029/2004JA010634, 2005b.

Papitashvili, V. O., Christiansen, F., and Neubert, T.: A new model of field-aligned currents derived from high-precision satellite magnetic field data, Geophys. Res. Lett., 29, 28-1, doi:10.1029/
2001GL014207, 2002.

Potemra, T. A.: Field-aligned (Birkeland) currents, Space Sci. Rev., 42, 295-311, 1985.

Rasmussen, C. E., Schunk, R. W., and Wickwar, V. B.: A Photochemical Equilibrium Model for Ionospheric Conductivity, J. Geophys. Res., 93, 9831-9840, 1988.

Ridley, A. J., Gombosi, T. I., and DeZeeuw, D. L.: Ionospheric control of the magnetosphere: conductance, Ann. Geophys., 22, 567-584, 2004,

http://www.ann-geophys.net/22/567/2004/.

Robinson, R. M. and Vondrak, R. R.: Measurements of E region ionization and conductivity produced by solar illumination at high latitudes, J. Geophys. Res., 89, 3951-3956, 1984.

Stauning, P.: Field-aligned ionospheric current systems observed from Magsat and Oersted satellites during northward IMF, Geophys. Res. Lett., 29, 8005-8008, 2002.

Stern, D. P.: The Origins of Birkeland Currents, Rev. Geophys., 21, 125-138, 1983.

Sugiura, M.: Identifications of the polar cap boundary and the auroral belt in the high-altitude magnetosphere - A model for fieldaligned currents, J. Geophys. Res., 80, 2057-2068, 1975.

Tanaka, T.: Generation mechanisms for magnetosphere-ionosphere current systems deduced from a three-dimensional MHD simulation of the solar wind-magnetosphere-ionosphere coupling processes, J. Geophys. Res., 100, 12057-12074, 1995.

Tsyganenko, N. A.: A global analytical representation of the magnetic field produced by the region 2 Birkeland currents and the partial ring current, J. Geophys. Res., 98, 5677-5690, 1993.

Tsyganenko, N. A.: Effects of the solar wind conditions in the global magnetospheric configurations as deduced from databased field models (Invited), in: International Conference on Substorms, edited by: Rolfe, E. J. and Kaldeich, B., vol. 389 of ESA Special Publication, pp. 181-185, 1996.

Tsyganenko, N. A. and Sitnov, M. I.: Modeling the dynamics of the inner magnetosphere during strong geomagnetic storms, J. Geophys. Res. (Space Physics), 110, 3208, doi:10.1029/ 2004JA010798, 2005.

Vickrey, J. F., Vondrak, R. R., and Matthews, S. J.: The diurnal and latitudinal variation of auroral zone ionospheric conductivity, J. Geophys. Res., 86, 65-75, 1981.

Waters, C. L., Anderson, B. J., and Liou, K.: Estimation of Global Field Aligned Currents Using the Iridium System Magnetometer Data, Geophys. Res. Lett., 28, 2165-2168, 2001.

Weimer, D. R.: Maps of ionospheric field-aligned currents as a function of the interplanetary magnetic field derived from Dynamics Explorer 2 data, J. Geophys. Res., 106, 12889-12902, 2001.

Zanetti, L. J., Baumjohann, W., and Potemra, T. A.: Ionospheric and Birkeland Current Distributions Inferred From the MAGSAT Magnetometer Data, J. Geophys. Res., 88, 4875-4884, 1983.

Zanetti, L. J., Potemra, T. A., Bythrow, P. F., Iijima, T., and Baumjohann, W.: Ionospheric and Birkeland current distributions for northward interplanetary magnetic field - Inferred polar convection, J. Geophys. Res., 89, 7453-7458, 1984.

Zmuda, A. J. and Armstrong, J. C.: The diurnal flow pattern of field-aligned currents, J. Geophys. Res., 79, 4611-4619, 1974a.

Zmuda, A. J. and Armstrong, J. C.: Diurnal variation of the region with vector magnetic field changes associated with field-aligned currents, J. Geophys. Res., 75, 2501-2502, 1974 b. 
Zmuda, A. J., Martin, J. H., and Heuring, F. T.: Transverse Magnetic Disturbances at 1100 Kilometers in the Auroral Region, J. Geophys. Res., 71, 5033-5045, 1966.
Zmuda, A. J., Armstrong, J. C., and Heuring, F. T.: Characteristics of Transverse Magnetic Disturbances Observed at 1100 Kilometers in the Auroral Oval, J. Geophys. Res., 75, 4757-4762, 1970. 